girl had several similar attacks, for which she was treated by Mr. Pritchard at our dispensary, and relieved by the establishment of the menstrual secretion, which, up to that time, had not been accomplished. For a couple of months preceding these last attacks she had not menstruated, and for two or three days she had been drowsy, and complaining of slight headach. Her friends describe her attacks as commencing with drowsiness, and advancing gradually to profound sleep. Her longest sleep has been six-and-thirty hours. My patient, on the lay following my first visit, was seized in a similar way, but on this occasion the sleep continued only three hours, and then terminated in an epileptic fit, from which she was recovered by a bleeding of eighteen ounces. The next attack, two days after, was one of common hysteria. At this time she had a blister applied to the hypogastrium, and was taking aloetic pills. The menstrual secretion appeared in a few days after; she had no later attack, and has continued in the enjoyment of good health. I am, Sir, your obedient servant,

W. Travers Cox, M.B., Member of the College of Plyysicians.

Great Yarmouth, June 18, 1835.

\section{CONCENTRATED INFUSIONS.}

\section{To the Editor of The LanceT.}

Sra,-In two numbers of your excellent publication there have appeared the remarks of two different correspondents, relative to the purity of the mode of preparation of many articles in the Pharmacopoia by druggists an 1 manufacturers generally. Among the preparations alluded to, one of the most prominent was the concentrated infusions, and the remarks in favom of these, in the latter communication, appear to me to be so very erroneous and so well calculated to mislead, that I cannot resist the inclination to offer a reply.

For the last eight years $I$ have been actively and extensively engaged in the study and operations of pharmacy, and have had occasion during that time to devote particular attention to the different proccsses for making the concentrated essences. Your correspondent, with the best motives I doubt not, states that the forms given by the Pharmacopoia for making infusions ought to be completely superseded by the superior convenience of the concentrated, which, with the exception of Inf. Sennæ, he praises in very high terms. Now, sir, so far from this being just, I firmly believe that the Inf. Sennæ is the only one of them which is good for anything at all. I think the reasons I subjoin will bear me out in this opinion.

I have cause to know from personal experience that almost the whole of the bitter concentrated infusions, as usually prepared, have their flavour given them, not by the respective drugs as is professed, but from the bitter principle extracted from quassia, and termed by Dr. Thomson quassin, which it is well known can be completely obtained by spirit and water, and which, more or less diluted, with different adjuncts to form a colour, is, as 1 have just said, the basis of the above-mentioned medical agents. With regard to the infusions of orange-peel and gentian, I can only say that the diluted product obtained from any sample of the strong article that $I$ have ever yet seen, has been totally different in appearance, taste, and smell, from the product obtained in the usual manner, being infinitely less pungent and grateful. Indeed it must be evident to any person who has devosed the least attention to the subject, that decoction will render any substance totally inert the active principles of which are volatile, or have any portion of extractive matter: one trial will speedily convince anybody that the bitter taste also is almost entirely lost by long coction. Inf. Sennx Concent. also, as commonly made, by boiling the leaves, is not of much worth, but if pre. pared by first forming a proportionately strong infusion, pressing it, adding a sufficiency of spirit to precipitate the mucilaginous matter, and, lastly, evaporating this product slowly in a water-bath to the just proportion, an article may be produced which will not deposit its cathartine, and which will possess a similar purgative effect to the infusion made in accordance with the Pharmacopœia.

I should not have ventured, sir, to trouble you with these remarks, had I not been apprized of the increasing circulation of the preparations in question, which I well know would not be the case if the medical profession were properly informed of their nerits. I have the honour to be, sir, your most obedient,

Pharmaceutical Assistant to the St. A.try-le-bone Infirmary. 